\title{
A escola e famílias de territórios metropolitanos de alta vulnerabilidade social: \\ práticas educativas de mães "protagonistas" *
}

\section{HAMILTON HARLEY DE CARVALHO-SILVA}

Centro de Estudos e Pesquisas em Educação, Cultura e Ação Comunitária, São Paulo, SP, Brasil

ANTÔNIO AUGUSTO GOMES BATISTA

Centro de Estudos e Pesquisas em Educação, Cultura e Ação Comunitária, São Paulo, SP, Brasil

LUCIANA ALVES

Centro de Estudos e Pesquisas em Educação, Cultura e Ação Comunitária, São Paulo, SP, Brasil

\section{INTRODUÇÃO}

Este artigo é parte de uma investigação mais ampla que teve como objetivo central explorar as relações com a escola de famílias que vivem em territórios metropolitanos de alta vulnerabilidade social. Ele se volta para o exame de esforços educativos de um grupo de mães dessas famílias cuja relação com a instituição escolar é marcada por uma tendência ao protagonismo.

* Texto apresentado no Grupo de Trabalho Sociologia da Educação (GT14), da 35a Reunião Anual da Associação Nacional de Pós-Graduação e Pesquisa em Educação (ANPEd), realizada em Porto de Galinhas/Ipojuca (PE), de 21 a 24 de outubro de 2012. 
A problemática da investigação mais geral se situa no quadro dos estudos sobre o efeito educativo das desigualdades socioespaciais. Dado o fenômeno da segregação do espaço físico e social nas metrópoles brasileiras, pesquisas vêm constatando a presença, em contextos semelhantes, de um efeito de território ou de lugar (Ben Ayed; Broccolichi, 2008; Maloutas, 2011), vale dizer, de uma limitação das oportunidades educativas oferecidas pelos estabelecimentos de ensino localizados em espaços segregados, resultante das desigualdades condicionadas pelo isolamento social, cultural e espacial de sua população (Érnica; Batista, 2011, 2012; Ribeiro; Katzman, 2008).

Fenômeno por excelência complexo, suas explicações enfatizam tanto características da oferta de serviços quanto da demanda. Entre as investigações que se voltam para as características da demanda na construção do efeito da segregação socioespacial sobre as desigualdades escolares estão aquelas que recaem sobre as características das famílias, especialmente para suas disposições éticas e culturais e sobre suas expectativas escolares. Nesse caso, uma corrente explicativa enfatiza a emergência, nos territórios segregados - expostos a fortes estigmas e a uma fraca presença do Estado -, de subculturas ou padrões culturais que ameaçariam a coesão social e a integração das populações desses territórios ao tecido social, especialmente pela via da escola, supostamente por elas desvalorizada (para uma síntese, ver Sant'Anna, 2009).

Certamente, podem ser encontradas, entre essas populações, famílias expostas a riscos tão grandes que as possibilidades de reprodução social, especialmente aquelas por meio de estratégias educativas (Bourdieu, 1999), acham-se fortemente comprometidas (ver na sequência). São, porém, variadas as práticas e os estilos educativos no interior de um mesmo grupo social (Montandon, 2005). Outras investigações sobre famílias de meios vulneráveis tendem, além disso, a questionar a suposta desvalorização da escola por essas famílias (Sant'Anna, 2009). Ainda que seja essa a representação generalizada sobre a relação de famílias das camadas populares com a instituição escolar, tal representação seria, segundo determinados estudos, um efeito da universalização da matrícula e da inflação de diplomas, fortemente influenciado pelo discurso dos agentes escolares (Charlot, 1997; Dubet, 1997; Lahire, 2004).

No quadro dessa problemática, explorar as complexas - e variadas - relações das famílias desses meios com a escola foi o interesse que animou a pesquisa. Ela foi realizada com um grupo de 12 famílias moradoras de um território de alta vulnerabilidade social, situado na periferia da Zona Leste de São Paulo.

A análise apreendeu dois grupos de famílias, construídos de acordo com a intensidade de seus esforços na escolarização dos filhos:

a) Famílias cujos esforços eram limitados pela precariedade das condições de vida e pela doença mental materna $(n=4)$;

b) Famílias que realizavam esforços constantes e regulares, por meio da ação direta da mãe ou pela delegação a terceiros $(n=8)$. 
Os dois grupos demonstraram igualmente uma expectativa positiva em relação à escola e à escolarização de seus filhos, contrariando, portanto, as representações que supõem haver uma desvalorização ou indiferença de famílias pobres e, especialmente, moradoras de territórios vulneráveis em relação à vida escolar dos filhos. Ambos ainda realizavam, igualmente, esforços para a própria escolarização. As precariedades das condições de vida do primeiro, entretanto, e uma menor homologia entre suas práticas educativas e as escolares fazem com que seus esforços se dirijam, sobretudo, para assegurar o acesso das crianças à escola e a permanência nela. Em suas vidas, esses não são esforços desprezíveis.

No interior do segundo grupo, encontrou-se, porém, um subgrupo de mães que se distinguia das demais do próprio grupo, por assumir um "protagonismo" na escolarização dos filhos, realizando fortes e mais autônomos investimentos em sua educação: tomavam a iniciativa de buscar contatos com a escola; tentavam romper com a setorização da matrícula, evitando o estabelecimento de ensino para o qual a vaga de seus filhos havia sido designada e incorporavam em suas rotinas diárias práticas de acompanhamento escolar $(\mathrm{n}=5)$.

Quem são essas mães? Como se caracterizam esses esforços? Quais as reações das escolas a eles? Que propriedades sociais das mães ou do grupo familiar podem explicá-los? O artigo procura avançar nas respostas a essas perguntas.

\section{METODOLOGIA}

Para a coleta de dados, foram realizadas entrevistas semiestruturadas e, secundariamente, observou-se a família, suas interações com a vizinhança imediata (no período mínimo de um dia e, no máximo, de três). Foram estudadas, como se indicou, 12 famílias. Elas foram escolhidas entre as participantes de um projeto social dirigido a mães moradoras de um território de alta vulnerabilidade social da extrema periferia de São Paulo. ${ }^{1}$

Foram buscadas famílias que, embora não se distanciassem excessivamente do ponto de vista socioeconômico, apresentavam alguns traços distintivos, especialmente em relação à escolaridade da mãe (de nenhuma no nível médio), à renda (de $R \$ 500,00$ a $R \$ 1.700,00$ ) e ao total de filhos matriculados (de 1 a 4 crianças). Essa variação objetivou representar a heterogeneidade que se sabia presente no território. A seleção dos participantes se deu por meio de trezentas fichas cadastrais do projeto, número de famílias até então por ele atendidas. Apesar de essas famílias

1 O projeto tem por objetivo contribuir para a melhoria sustentável da qualidade de vida de famílias em situação de alta vulnerabilidade social, por meio de seu acompanhamento. As implicações da escolha sobre as características do grupo, bem como sobre a análise, são explicitadas na conclusão deste trabalho. 
serem parte de um mesmo território altamente vulnerável, apresentavam distintos níveis de vulnerabilidade social. ${ }^{2}$

O contato com as famílias se deu com as mães. O trabalho no campo, desde as primeiras incursões, permitiu observar que durante o dia eram as mulheres que se tornavam visíveis no território, cuidando de afazeres domésticos, levando e buscando as crianças na escola. Por essa razão, a pesquisa centrou-se nelas, até porque a maioria dos pais passava o dia fora de casa, no trabalho.

Apesar da setorização da matrícula, que privilegia a indicação de estabelecimentos de ensino próximos da residência da família, foi possível garantir no grupo certa diversidade de escolas em que as crianças estavam matriculadas, o que contribuiu para se compreender a construção de hierarquias escolares organizadas pelas mães e os esforços por elas empreendidos na tentativa de escolha de estabelecimentos de ensino. Um dos resultados importantes da pesquisa mostrou que praticamente todas elas - como se verá mais adiante - tentavam, por diferentes razões, escolher a escola onde matricular os filhos e, especialmente, evitar a escola situada no bairro em que viviam e na qual, em geral, suas crianças são compulsoriamente matriculadas pela compatibilização automática da matrícula, sistema adotado em regime de colaboração pela prefeitura e pelo estado de São Paulo (Alves; Batista; Érnica, 2012).

O trabalho de campo lançou mão da observação - de inspiração etnográfica da vida da família e de alguns aspectos do cotidiano no território por meio de visitas aos locais de sociabilidade e aos equipamentos educacionais e culturais disponíveis; 6 reuniões com a assistente social parceira para triangulação de dados; 25 visitas à casa das 12 famílias no período de março a outubro de 2011 e entrevistas com as crianças por meio da exploração de materiais escolares. Os dados recolhidos foram sistematicamente organizados em diários de campo; relatórios de visita descritivos e planilhas de dados primários.

A análise desse conjunto de dados foi feita primeiramente por meio de retratos sociológicos (Lahire, 2004), o que garantiu o respeito às singularidades familiares, ao mesmo tempo em que, permitindo estabelecer comparações entre elas, possibilitou a apreensão de regularidades e padrões comuns. A apreensão desses padrões possibilitou, por sua vez, a construção de grupos de famílias em razão de suas relações com a escola e de suas práticas e esforços educativos.

\section{O TERRITÓRIO}

O bairro onde vivem as mães é uma comunidade de aproximadamente 5,5 $\mathrm{km}^{2}$, localizada na periferia da Zona Leste de São Paulo, que agrega as características

2 Outras propriedades importantes levadas em conta foram a idade do casal, o número de filhos, a ocupação do marido. Uma propriedade não considerada inicialmente, mas que se mostrou muito importante, foi o local de moradia no bairro, assim como o tipo de moradia (se alugada ou não, se de ocupação legalizada ou não, se localizada em área de enchente ou não, se com local de proteção para as crianças ou não). 
mais gerais das periferias dos grandes centros urbanos. Sua particularidade emerge das fronteiras naturais e urbanas, que a tornam um território demarcado e isolado. Apesar de muito próxima do estruturado centro comercial da subprefeitura a que pertence, é acessível, a pé, quase que exclusivamente por uma passarela de madeira improvisada que se projeta sobre a linha de trem:

Uma rodovia, dois córregos e uma linha de trem delimitam as bordas de uma comunidade da Zona Leste da cidade de São Paulo. Sem saneamento básico e rede de esgoto, o improviso das mangueiras que compõem o encanamento das casas explicita a relação paradoxal entre a criatividade e a vulnerabilidade social de seus moradores. Cada um deles traz ao espaço público os fios singulares de sua história, para tecer possibilidades de convivência familiar e comunitária na trama desagregada de um território onde não há creche, escola de educação infantil - EMEI, Unidade Básica de Saúde - UBS e cobertura do Programa de Saúde da Família - PSF. (Lomônaco; Garrafa, 2009, p. 27)

As constantes enchentes de verão imprimem nessas famílias um modo de vida repleto de preocupações e de desafios para se realizar as tarefas comumente mais simples, como comprar pão ou ir à escola: "imagina, em dia de chuva, com enchente, ter que atravessar a enchente para ir pra escola. Tem que ter muita vontade mesmo" (depoimento de Laura). ${ }^{3}$

O tráfico é uma presença constante no cotidiano das famílias, embora raras vezes abordem o tema diretamente. Em alguns momentos, foram presenciadas situações de uso de maconha por jovens na frente das crianças (o que constrangeu as mães). Muitas delas temem o consumo de drogas pelos filhos, especialmente na saída da escola: "tenho medo de deixar ele na rua. Ele vai achar que é normal. Todo mundo fumando, todo mundo vendendo assim na rua, como é que eu vou dizer pra ele que isso não pode?" (depoimento de Eva).

\section{MÃES PROTAGONISTAS E SEUS ESFORÇOS}

Entre as famílias integrantes do segundo grupo - das famílias que realizavam esforços mais regulares e intensos para a escolarização dos filhos -, um conjunto de cinco mulheres tem como traço distintivo uma atuação marcante em diferentes instâncias de seu cotidiano: na família, na escola e, algumas delas, no próprio território. Essa atuação se dá de tal maneira que essas mães podem ser caracterizadas como protagonistas, pois assumem ativamente a condução da administração da casa, da educação dos filhos e, especialmente, de assegurar sua adequada escolarização.

3 Para preservar a identidade dos entrevistados participantes da pesquisa, foram utilizados nomes fictícios. 
Entre as protagonistas estão Laura, Eva, Rosa, Ana e Edna; mulheres nordestinas que se autoclassificam como negras (com exceção de Ana e Rosa), com idade variando entre 25 e 42 anos.

A renda com a qual se sustentam é bastante variável: de um a quase quatro salários mínimos. Mesmo nas famílias com renda mais baixa, entretanto, esses recursos são mais facilmente administrados, pois nenhuma tem mais de dois filhos, o que sugere a prática do controle de natalidade como uma estratégia de reprodução social do grupo familiar.

A renda do grupo provém de trabalho remunerado, formal e/ou informal, e, no caso de Laura, soma-se ao salário do marido o benefício recebido pelo filho deficiente. Chama a atenção o fato de essas mulheres desempenharem um papel bastante ativo na administração dos recursos financeiros familiares, decidindo como gastar o dinheiro e não dependendo diretamente da permissão do marido para isso, como observado em outro grupo. Entre essas mulheres, quatro exercem atividades remuneradas, sendo que Edna possui rendimento maior que o de seu companheiro. Apenas Laura se dedica exclusivamente às tarefas domésticas, pois deve especial cuidado ao filho com deficiência. ${ }^{4}$

Apesar de terem tido uma escolarização irregular e extemporânea, apresentam fortes expectativas educacionais, aspirando a uma escolarização longa não apenas para os filhos, mas também para si mesmas. Esse traço pode se dever ao fato de todas terem sido selecionadas em um projeto social que, entre outras proposições, incentiva as mães a retomarem os estudos (embora esse traço não tenha sido encontrado em todas as participantes da pesquisa). Do grupo, duas das cinco mães, Ana e Rosa, frequentam a Educação de Jovens e Adultos (EJA). Edna completou o ensino médio aos 22 anos (bem antes de ingressar no projeto) e atua como professora particular no bairro, sendo reconhecida como uma excelente alfabetizadora; Laura e Eva estudaram, porém, até a quarta série do ensino fundamental, quando abandonaram definitivamente a escola.

Em sua trajetória, o grupo tem em comum a experiência de dificuldades na relação com a escola e, mesmo Edna, a mais escolarizada entre elas, experimentou o fracasso nos primeiros anos de estudo: "fui passando, passando, passando e cheguei na quinta série sem saber ler e escrever. Daí minha mãe me colocou na primeira série de novo com onze anos, aí eu fiz tudo de novo e aprendi” (depoimento de Edna).

Essa trajetória e o desejo de romper com ela possivelmente influenciam a maneira como as mães encaram a vida escolar dos filhos: "eu incentivo muito o estudo, tem que ir pra escola, pois é a única coisa de bom que a gente pode dar" (depoimento de Laura). Tal influência provavelmente também se origine de uma das expectativas dessas famílias em relação à educação, uma que está baseada na

4 Como se verá adiante, Edna dá aulas particulares e é doceira. Ana, embora esteja atualmente desempregada, na época da coleta trabalhava como ajudante de lavanderia num hospital. Eva e Rosa são diaristas, embora a última também faça "bicos" cuidando de crianças e fazendo doces e salgados para festas. 
avaliação positiva do papel da certificação do diploma no acesso, hoje, a postos de trabalho "na cidade", em oposição ao passado, na "roça" ou no "interior". Isso faz com que julguem que a "única coisa boa" que podem deixar aos filhos é a escola. Ela é caracterizada como um bem que, embora não seja material, encerra as expectativas de possível ascensão social, tendo em vista as condições de pobreza e exposição a riscos sociais a que as participantes da pesquisa estão sujeitas.

Talvez por conta das altas expectativas em relação à escola, todas se esforcem para garantir a escolarização dos filhos por meio de distintos expedientes. Demonstram possuir em suas dinâmicas intrafamiliares maior consonância com 0 universo escolar, ou seja, (a) incorporam rotinas de leitura e estudos, (b) criam tempos e espaços para realização de atividades escolares, (c) acompanham o desempenho escolar pelas notas e boletins, (d) verificam as atividades e os comunicados contidos no caderno, (e) investem na compra de materiais escolares e em recursos para aprimoramento da aprendizagem, (f) participam espontânea e ativamente das reuniões de pais e mestres para tomar conhecimento sobre o desempenho escolar dos filhos e (g) buscam mecanismos para apoiar os filhos nas atividades escolares.

Além desses esforços - ou em razão deles -, essas mães também buscam escolher ou evitar estabelecimentos de ensino para matricular seus filhos, tomando como critério de escolha atributos que os caracterizem como "boas escolas". Ao que parece, tal escolha se realiza em negativo, ou seja, caracteriza-se muito mais pela evitação de determinadas escolas cujo modo de funcionamento se assemelha às dinâmicas do território vulnerável em que moram e estudam os participantes da pesquisa, pois, como se verá na sequência, ele é, para algumas mães, fonte de perigo a ser, assim como algumas escolas, evitado.

\section{ESFORÇOS EDUCATIVOS}

A escolha/evitação dos estabelecimentos de ensino do território se baseia numa hierarquização das instituições. A hierarquização é uma prática comum a todas as mães do estudo, que utilizam como critérios algumas características das escolas, tais como: (a) ordem disciplinar capaz de manter os alunos distantes da violência e dos conflitos que identificam no bairro em que residem; ${ }^{5}$ (b) atividades educativas diversificadas (excursões, passeios, atividades extras) que acenam para maior investimento e melhores condições no/de ensino; (c) presença de programas e projetos que possam aproximar a criança e sua família de benefícios sociais; (d) perfil socioeconômico

5 Vale realçar que a presença de mecanismos disciplinares e a disponibilidade de benefícios sociais estão sempre presentes na hierarquização dos estabelecimentos de ensino realizada pelas mães e parecem se relacionar mais diretamente com as características do território e com as condições socioeconômicas a que as famílias estão submetidas. No território vulnerável, a escola tende a ser chamada, em virtude da ausência de outros equipamentos públicos, para buscar a resolução de um conjunto de problemas sociais mais gerais, tornando-se depositária de expectativas sobre segurança, saúde e assistência social das famílias (Érnica; Batista, 2011, 2012). 
e territorial dos estudantes, com vistas a diminuir a influência negativa de colegas moradores da mesma comunidade; (e) organização e modos da gestão institucional.

Contudo, as mães protagonistas valorizam de modo mais intenso os critérios que se relacionam à existência de diferenciais que possam significar uma melhor qualidade de ensino.

Laura relatou que a escola promove diversos passeios com os alunos para o cinema, museu, teatro, e completou: "Eu acho isso muito importante [os passeios]. O pessoal aqui não tem oportunidade de levar os filhos para esses lugares. Assim eles podem ter essa experiência. [...] Agora, o Rubens [avaliada pelas mães como a pior escola] tem muita aula vaga. Os professores faltam muito. Desse jeito, como é que o professor vai avaliar se o aluno tá apto ou não para ir pro outro ano? Aqui no Rubens não tem exigência de EMEI. No Brigadeiro [avaliada pelas mães como uma das melhores escolas] tem. A EMEI é importante também". (Trecho do retrato sociológico e depoimento de Laura)

Mesmo que todas as mães façam hierarquizações, apenas aquelas que dispõem de mais recursos conseguem efetivar sua escolha. $\mathrm{O}$ êxito na escolha da "melhor" instituição ou na evitação da "pior" depende das relações que essas mães possuem no bairro, do status de que desfrutam na comunidade e dos contatos que estabelecem com os agentes públicos que atuam nos diferentes equipamentos da região. Ou seja, conhecer um professor, ser amiga da secretária da escola, ter uma relação positiva com a diretora, ter ligação com um agente comunitário ou educador de organização não governamental (ONG) é fundamental. No mesmo sentido, a possibilidade de concretização da escolha relaciona-se ao conhecimento que essas mães possuem sobre o funcionamento e organização do sistema de ensino e das escolas.

Para não perder a matrícula da filha, Edna disse que concordou consigo mesma que, durante a primeira série, Paula frequentaria a EE Rubens [em que a filha foi matriculada pelo sistema automático], enquanto ela buscaria alternativas para solicitar uma transferência. Edna acionou conhecidos no bairro que a ajudaram nesse processo. Ela contou: "Minha vizinha fez um cadastro no Teixeira pra mim e conversou com o diretor para conseguir uma vaga pra Paula. Ela tinha conhecimento com o diretor [esfregando um contra o outro o dedo médio e o indicador da mesma mão]. Quando chegou dezembro, o diretor do Teixeira me chamou. Fiquei surpresa. Achei que ele não ia chamar, porque é uma dificuldade conseguir vaga lá. Então fiz a transferência da Paula". (Trecho do retrato sociológico e depoimento de Edna)

Recusando a primeira opção sugerida pela Diretoria de Ensino, Laura tentou a matrícula na Escola Municipal Anísio Teixeira [melhor avaliada pelas mães], mas foi informada da indisponibilidade de vagas. Munida de laudos médicos, que atestavam a deficiência do filho, justificativas e argumentos, retornou à 
Diretoria e exigiu a matrícula de Wesley no "Anísio". Após período de negociações e apoio da assistência social, Wesley finalmente foi matriculado nessa escola. (Trecho do retrato sociológico de Laura)

Os excertos revelam os conhecimentos de Laura e Edna sobre o funcionamento do sistema de ensino (especialmente de matrícula) e como esse conhecimento possibilitou a formulação de estratégias para que elas pudessem ter sua escolha contemplada: conhecem as instâncias de decisão (direção da escola ou Diretoria de Ensino); fazem uso de um capital de relações sociais, no caso de Edna, ou possuem uma consciência de direitos e do modo de fazê-los valer, no caso de Laura. Contudo, essa não é uma característica de todas as mães protagonistas, já que a maioria lamenta a escola indicada pelo poder público, mas não possui recursos para revertê-la. Por isso, os filhos mais novos das famílias de Rosa e de Eva estudam na escola menos prestigiada da região. Vale destacar que, em São Paulo, a escolha de estabelecimento de ensino pelas famílias vem sendo cada vez mais dificultada pela maior rigidez do processo de matrícula setorizada (Alves; Batista; Érnica, 2012), que condiciona a matrícula à maior proximidade entre residência e escola.

Há seis anos era comum a EMEI encaminhar para o Anísio [escola bem avaliada pelas mães]; depois começou encaminhar pro Rubens [escola mal avaliada]; e é muito difícil transferir, só algumas mães conseguem. Os pequininhos agora estudam tudo aqui no Rubens. (Depoimento de Ana)

$\mathrm{Na}$ construção das hierarquias, a escola e seus agentes, nominalmente os professores, são, na maior parte das vezes, eximidos da responsabilidade pela falta de prestígio da instituição. Os problemas são atribuídos aos alunos da escola. Trata-se, nesse caso, sempre da escola que atende à própria vizinhança e que concentra em seu corpo discente as crianças e jovens do bairro, identificados por uma de suas moradoras como "moleque de favela":

Como pode ter tanta briga dentro de uma escola? Lá estuda muito moleque de favela, e moleque de favela você sabe como é, né? Tem que ficar de olho. Os mais velhos chama os mais novos para dar um rolê. Passear mesmo. E chamam para passear pra quê? Eu bem sei a intenção desses moleques. Tem que ficar em cima. Tem que controlar. (Depoimento de Laura)

A avaliação da escola feita pela consideração de seu corpo discente e morador da vizinhança não é atitude exclusiva das mães protagonistas. Num depoimento, uma mãe, também com significativa participação na escolarização dos filhos, assim avaliou a mesma escola: "Eu tinha uma visão ruim do Rubens, sabe? Daí eu entendi que não é a escola que não presta. São as pessoas que frequentam a escola que não prestam. Não é a escola em si” (depoimento de Vanda).

Os exemplos mostram que, muitas vezes, a avaliação da escola se pauta num possível reconhecimento - ainda que parcial e próximo do preconceito - do efeito negativo de pares, provocado pelo agrupamento de alunos que carregam 
as características do território para a escola. Apesar disso, algumas vezes as mães manifestam a consciência de que nem sempre o problema da escola está em seus alunos. Quando elas avaliam o baixo desempenho das crianças, os professores são também responsabilizados, pois, como conclui Edna: "tem aquele professor que não quer saber de nada”.

Concomitantemente à busca de evitação de escolas, as mães protagonistas empreendem outros esforços para, após a matrícula, garantir uma adequada trajetória escolar.

Um desses esforços é a participação no cotidiano das escolas, sobretudo em reuniões. De maneira geral, as mães se esforçam para participar de reuniões nas escolas, não apenas em situações nas quais são incentivadas a isso - no caso das reuniões de pais -, mas também com a proposição de ajuda e questionamentos sobre a qualidade do ensino e a maneira como a instituição trata seus filhos:

Eu sempre pergunto do meu filho e elas falam que ele só conversa. Aí eu pergunto do desenvolvimento e elas falam que ele está bem, mas não sei por que elas falam que ele está bem. Eu não acho que ele está bem na escola. (Depoimento de Eva)

Vê-se que, enquanto a escola está preocupada com problemas de disciplina, a mãe (revelando um inesperado conhecimento da linguagem escolar) está preocupada com o "desenvolvimento" ou "aprendizado". Segundo ela, trata-se de uma reclamação que ela faz recorrentemente nas reuniões de pais.

Como se pode observar, as expectativas de construção de uma trajetória escolar bem-sucedida não são correspondidas em todos os casos das mães protagonistas. Eva se preocupa porque o filho não está avançando e porque a escola não está se dando conta disso. No grupo, apenas ela vê frustrada a possibilidade de sucesso escolar.

As críticas à escola se repetem em muitas famílias do estudo, mas as mães com uma atuação mais protagonista têm condições de questionar professores e diretores a respeito dos problemas que percebem - e esse questionamento nem sempre é bem-aceito por eles. Eva, por exemplo, tentou averiguar com a professora de seu filho o motivo da inexistência de lição de casa, questionamento feito durante uma reunião de pais. Segundo ela, recebeu como resposta uma ameaça: "Vocês estão reclamando que eu não passo lição de casa? Então vocês vão ver só”.

O modo como professores e outros funcionários das escolas lidam com o protagonismo das mães é bastante diverso e depende do prestígio atribuído a elas. Como todas são provenientes de um território não somente vulnerável, mas também estigmatizado, é de se esperar certa tensão nos momentos em que famílias criticam a atuação da escola. A única mãe que parece ter uma inserção mais bem-aceita pela escola é Edna, que tem um papel importante para a escolarização das crianças do território onde vive. 
Esse papel está ligado a outro esforço educativo empreendido por essas mães, relacionado à reparação do desempenho escolar. Edna oferece aulas de reforço com foco na alfabetização e garante que alfabetiza

todo mundo em três meses. Tenho criança da primeira até a quarta série. Aqui sou conhecida como a tia Edna. Eu tenho lista de espera para pegar crianças. Mas antes eu tenho que alfabetizar esses primeiro. (Depoimento de Edna)

Edna é uma das alternativas presentes no território para reparar os problemas de aprendizagem, comuns a muitas crianças do estudo. Entretanto, essa opção só é possível para aquelas famílias que, além de possuírem expectativas educacionais diferenciadas, têm melhores condições de vida ou recursos financeiros para pagamento das aulas de reforço.

Segundo Edna, as professoras das escolas da região, quando percebem a dificuldade dos alunos para se alfabetizar, indicam aos pais que contratem seus serviços, que parecem surtir efeito, tendo em vista os cadernos dos alunos que demonstram, entre as primeiras e as últimas tarefas, um progresso não garantido pela escola.

Tentando explicar por que professores formados para lecionar indicam o trabalho de alguém sem formação específica, Edna faz referência a problemas de ordem estrutural enfrentados por escolas públicas - "como você vai dar atenção para quarenta alunos de uma vez?" - e à suposta participação limitada dos pais na vida escolar de seus filhos. Chama, porém, a atenção ainda para professores que apresentam sérias limitações:

Os professores têm boa vontade em ensinar, mas a bagunça não permite. Tem muita criança atentada e as mães só ficam criticando, mas tem muita professora boa. Eu vejo que elas ensinam. Eu acompanho o caderno deles da escola e vejo que elas tão tentando ensinar, mas não dá pra dar atenção para todo mundo. As mães nem olham o caderno dos filhos. Tem mães que são mais rígidas e tem outras que não estão nem aí. Por isso é um conjunto de coisas. Tem criança que não sabe nada, que tem dificuldade de aprender e aí o professor se acomoda. Acha que não tem jeito. Mas tem professor que é muito bom. Tem professor que todos os alunos na primeira série sabem ler. Agora, tem professor que dá todo dia receita. Eu vi isso. Eu chamei o pai aqui e falei pra ele reclamar na escola, porque não pode. Os pais têm que reclamar. Eu ensino e daí tem alunos que diz que a professora não ensinou ainda. Eu falo para eles: "você tem que aprender que quando ela ensinar você já sabe". (Depoimento de Edna)

Entre as mães protagonistas, apenas Eva tem um filho candidato ao serviço oferecido por Tia Edna. Seu nome consta na lista de espera para início do reforço. ${ }^{6}$ Os filhos das demais possuem um desempenho escolar que satisfaz as expectativas que suas mães depositam sobre eles.

6 Em junho de 2011, a lista para 2012 já tinha 45 candidatos. 
Além de esforços para reparar o insucesso, nas práticas das mães protagonistas há esforços para antecipar e intensificar, de modo direto, o trabalho da escola. Edna alfabetizou, segundo ela, sua filha aos 4 anos de idade. Laura, por sua vez, após receber recomendações de uma professora, passou a exigir e incentivar a prática de leitura da filha, como ilustra o trecho a seguir:

A mãe acredita que a filha gosta tanto de ler, porque, quando ela estava na primeira série, uma professora disse que era preciso incentivar os filhos a lerem de tudo. Não precisava só de livro para ler, poderiam ser incentivadas com panfletos de supermercado, outdoors, letreiros de ônibus. Laura disse ter criado esse hábito com a filha, pois ficava mostrando palavras em diversos lugares, perguntando o significado das coisas, até que ela passou a ler e a se interessar por tudo que era escrito. Lembrou que, nos trajetos de ônibus, a filha passou a ler mais rapidamente os outdoors que encontravam: "ela lia mais rápido que eu". (Trecho do retrato sociológico de Laura)

Pode ser observada na fala de Laura uma prática comum ao grupo das protagonistas, o incentivo à leitura dos filhos, que ocupa papel de destaque no cotidiano dessas famílias. Vale ressaltar que, com exceção dos filhos de Eva e de Rosa, que estudam na escola de menor prestígio, todos são incentivados ao empréstimo de livros na própria escola. Porém, Rosa, mesmo sem o incentivo escolar, como as outras, reproduz a prática da leitura como uma atividade frequente na rotina diária do lar: "Andressa é estudiosa; ela pega os livros lá na ONG. Sônia gosta dos livros com figuras e gosta que a irmã leia para ela”. Essa prática, na qual a irmã mais velha lê para a irmã mais nova, parece também ser corriqueira na família, pois Andressa sempre lê histórias para a irmã. É interessante observar, porém, que as mães nunca leem para os filhos. Segundo elas, tampouco os pais.

A aquisição de materiais e a organização do espaço da residência podem ser verificadas em todas as casas. Nelas há sempre livros didáticos, um lugar reservado para a realização das tarefas escolares - na maioria dos casos, a mesa da cozinha e parte do orçamento é reservada para custeio de materiais e passeios sugeridos pela escola. A aquisição de materiais permite entrever a existência de outro esforço educativo, dessa vez de ordem financeira, que auxilia no processo de intensificação do trabalho da escola.

O esforço ligado ao investimento financeiro é dificultado pelas condições de vida, sobretudo nas famílias que possuem menor renda e cuja casa é alugada. Isso explica por que Rosa é a única entre as mães protagonistas que não dispõe de computador com acesso à internet, ainda que para ela a aquisição de um computador permaneça um projeto a ser concretizado. Porém, mesmo não dispondo do equipamento em casa, ela incentiva o seu uso pelas filhas: "Andressa vai ao telecentro umas três vezes por semana. Ela faz pesquisa na internet e faz os trabalhos dela e me ajuda nos meus trabalhos" (depoimento de Rosa).

O computador é visto pelas mães desse grupo como um recurso de duplo objetivo. Se, por um lado, ele se presta a ser uma ferramenta para realização de 
pesquisas e tarefas escolares (portanto, ligado à intensificação do trabalho da escola), por outro ele cumpre o papel de preencher as lacunas da falta de lazer no bairro, tornando-se um aliado no controle do tempo livre das crianças, e das interações delas com o território, aspecto tratado mais adiante:

Além da TV, a internet surgiu como outra ferramenta de distração, de lazer e de uso das crianças: "agora tem internet aqui. Coloquei internet pras crianças. Eles ficam na televisão e na internet”. Laura disse que não controla o que os filhos acessam na rede, pois confia neles e acredita que a sua principal ferramenta é fazer pesquisa: "ela fica pesquisando as coisas dela de escola. Fica lendo as coisas dela lá”. A mãe não controla o conteúdo, mas disse controlar o tempo de uso do computador, pois é necessário que os dois filhos possam usá-lo. (Trecho do retrato sociológico de Laura)

A aquisição de livros segue as lógicas e recomendações escolares, por isso os impressos comprados são geralmente didáticos. $\mathrm{Na}$ casa de Ana, eles ficam em lugar de destaque na estante da sala, constituem-se, pois, em um bem simbólico a ser mostrado juntamente com outros bens: "uma estante preta com TV, aparelho de som, aparelho de DVD, enfeites na parte inferior e livros, na maioria didáticos, de português, história, geografia, matemática" (trecho do retrato sociológico de Ana).

$\mathrm{O}$ acompanhamento escolar também faz parte dos esforços educativos das mães. Ele é constante e termina por fazer com que a escola esteja bastante presente na rotina familiar e em sua organização. Todas conversam sobre o que se passou na escola quando os filhos voltam para casa e adotam sistemáticas de verificação dos cadernos para observar o desempenho e o desenvolvimento dos seus filhos na realização de tarefas: "olho o caderno dele todos os dias" (depoimento de Eva).

A realização do dever de casa é tratada por essas mães como algo prioritário,já que todas elas impõem a seus filhos a responsabilidade de primeiramente realizarem as atividades escolares, para então receber a permissão de brincar ou ver TV. Das mães, duas que voltaram a estudar - Ana e Rosa - condicionam a organização das tarefas domésticas com a realização de seus próprios deveres escolares, buscando fazer a lição de casa no mesmo momento em que seus filhos a fazem.

As crianças chegam da escola e almoçam junto com a mãe. Enquanto ela limpa a cozinha, os seus filhos descansam. Com tudo arrumado, sentam juntos à mesa para realizarem as tarefas escolares. Depois que terminam as tarefas, as crianças são autorizadas a brincar na área, ver TV ou interagir com o computador. (Trecho do retrato sociológico de Ana)

Quando a escola não oferece tais atividades, além de, segundo as mães, restringir as possibilidades de aprendizagem das crianças, diminuem também os recursos e as possibilidades que elas teriam de acompanhar e controlar seus filhos, como ilustra a fala de Eva. Segundo ela, por meio da sistemática de comunicação da escola por bilhetes, é possível condicionar atividades de recreação ao término das tarefas escolares: 
Antes eu sabia que ele não se comportava, que não fazia a lição, $e$ dai eu podia dizer: "não vai jogar bola, não vai ficar no computador, não vai ficar na frente da televisão"; daí eu fazia ele estudar. Agora eu não sei. Eu não posso falar isso pra ele. (Depoimento de Eva)

Além da prática dos estudos como elemento constitutivo do controle da rotina diária, duas dessas mães adotam práticas que visam, direta e explicitamente, restringir as relaçôes não institucionalizadas entre seus filhos e outras crianças do território, o que leva a crer na existência de um investimento educativo mais amplo que objetiva preparar os filhos para uma vida fora do território e que lhes oportunize conhecer outras realidades. Laura e Edna se destacam no grupo por realizarem tal interdição.

Edna não permite que a filha brinque na rua e a incentiva a realizar outras tarefas ao longo do dia, como desenhar, ver TV e interagir com o computador: "Paula não brinca na rua, prefiro que ela fique em casa". Pelas mesmas razões, Laura mantém seus filhos em casa e ainda organiza a rotina de modo que eles durmam no período da tarde quando não estão na escola:

O controle de Laura sobre os filhos limita as interações destes com vizinhos e parentes do bairro. Por isso, o principal lazer familiar é a TV por assinatura: "as crianças gostam muito de assistir televisão. Isso não é um problema pra mim. Assim eles ficam dentro de casa”. Outra maneira de regular o tempo livre dos filhos, comum às práticas educativas de Laura, é colocá-los para dormir todas as tardes após o almoço. (Trecho do retrato sociológico e depoimento de Laura)

Vale destacar que Laura busca limitar ao máximo os contatos sociais dos filhos, impedindo até mesmo interações com seus sobrinhos e com sua irmã e vizinha. Rosa, Ana e Eva também demonstram exercer o controle das interações de seus filhos com o território, ainda que de maneira menos radical que as anteriormente descritas. Ana permite que brinquem no quintal com os colegas, pois, ela declara:

não gosto que eles brinquem na rua, desde pequenos eu dizia para trazer os coleguinhas aqui em casa. Quando eles tão fora, você não vê o que acontece, vai que alguém machuca seu filho, ou seu filho machuca alguém. (Depoimento de Ana)

Rosa, por sua vez, mesmo sem considerar o bairro como um lugar perigoso, pois mora numa porção mais urbanizada do território, permite que suas filhas apenas brinquem no quintal, sob seu olhar protetor. Somente Eva, em razão da falta de espaço em casa, permite que seu filho mantenha contato com outras crianças nas interações durante os jogos de futebol, porém adotando mecanismos de supervisão dessa relação:

como é que eu vou trancar ele aqui em casa? Não tem espaço. Ele precisa andar um pouco. Eu deixo ele jogar futebol, espero um pouco, aí eu vou lá atrás vê se ele ta lá no campo mesmo. (depoimento de Eva) 
Assim, embora os esforços educativos das mães que compõem esse grupo sejam muito semelhantes, o modo como elas regulam os contatos dos filhos com o território tende a apresentar certa variação. $\mathrm{O}$ único traço em comum, nesse caso, é o uso das tarefas escolares como elemento de regulação, que se efetiva com propósitos distintos: de um lado visa à evitação do território e, por outro, possibilitar controlar as interações com ele.

Por essas razões, os esforços educativos empreendidos por esse grupo de mães refletem suas preocupações de garantir uma escolarização longeva e de qualidade para seus filhos, bem como de evitar a exposição aos riscos presentes no território. Tais esforços, portanto, orientam-se para a intensificação do trabalho da escola por meio da incorporação de rotinas de leitura, da realização das tarefas sempre acompanhadas pelas mães, da recuperação, quando necessário, e da compra de materiais. Além disso, são também usados como reguladores da interação das crianças com o território e do controle do tempo livre.

\section{CONCLUSÃO}

Contrariando a representação que equaciona a relação de famílias de meios muito vulneráveis de regiões metropolitanas e periféricas com a escola à indiferença ou a um forte distanciamento, a investigação identificou um grupo de famílias que, lideradas pelas mães, coloca na escola grandes aspirações e realiza, com os recursos que possui, acentuados investimentos para assegurar uma escolarização de sucesso para seus filhos.

Certamente, com maior peso nos casos de Edna e, especialmente, de Laura, esses esforços parecem estar associados a investimento maior, organizado em torno de uma busca de rompimento com o próprio território, com suas condições adversas. Daí a natureza, ao que tudo indica, primordialmente negativa das estratégias educativas desse grupo: trata-se de estratégias de evitação da escola situada no território que a setorização da matrícula impõe e do destino escolar que acarreta; trata-se de estratégias de evitação das relações de convívio e de sociabilidade dos filhos na rua e na escola com um universo do qual não querem fazer parte.

É dessa matriz negativa - essa é a hipótese levantada na pesquisa - que surgem os investimentos educativos das mães e a força maior ou menor de sua coerência, o que se pretende estudar de modo aprofundado num artigo posterior. Por ora, este parece ser, ao lado da história de cada família e de sua configuração social peculiar (Lahire, 2004), ${ }^{7}$ o único fator capaz de explicar as regularidades encontradas, bem como diferenças de intensidade e de coerência de esforços maternos (que não puderam aqui ser abordados).

Nenhuma propriedade social isolada se mostrou determinante: se, por exemplo, Edna é mais escolarizada e tem maior renda, Laura estudou até a quinta

7 As configurações familiares são consideradas nos retratos sociológicos feitos de cada família, ainda não publicados. 
série e sua renda está na faixa intermediária do grupo. A família de Rosa vive com apenas um salário mínimo e, até voltar a estudar, havia concluído apenas a quinta série. Se algumas vivem em locais mais protegidos e seguros para seus filhos, outras vivem em locais mais expostos ao tráfico e sem espaços para deixar os filhos brincarem sozinhos. A maior parte delas vive em zonas expostas a enchentes. Todas são católicas e frequentam regularmente a igreja do bairro. Todas contam com o apoio do marido ou companheiro. Pode-se, certamente, alegar que muitas de suas práticas resultam da influência do projeto social de que participam e por meio do qual foram selecionadas para a pesquisa. No entanto, nem todas as mães do projeto foram por ele influenciadas do mesmo modo.

Em relação às mães que compõem os demais grupos, tampouco há um traço ou propriedade social específica que distinga as protagonistas das demais, com exceção da inexistência, entre elas, de mães sem o apoio de um companheiro e também sem nível algum de escolaridade (Eva e Rosa, que tinham o nível mais baixo de escolaridade, haviam concluído a quarta série). Como já se indicou, irmãs foram classificadas em grupos distintos, uma delas sendo Laura, exemplo por excelência de mãe protagonista.

É preciso, portanto, buscar na história dessas mulheres e de suas famílias, bem como na configuração social peculiar que as produziu, as razões tanto de uma forte recusa ao território quanto, correspondentemente, de um forte investimento para evitá-lo e para ver na escola um importante meio para isso.

\section{REFERÊNCIAS}

Alves, Luciana; Batista, Antônio Augusto Gomes; Érnica, Maurício. Processos ocultos de seleção e evitação de alunos em escolas públicas. São Paulo: CENPEC, 2012. Informe de Pesquisa n. 6.

Ben Ayed, Choukri; Broccolichi, Sylvain. Quels liens entre réussite scolaire, inégalités sociales et lieu de scolarisation? Revue Ville École Intégration Diversité, Chasseneuil-du-Poitou, FR: CNDP, n.155, p. 66-72, déc. 2008.

Bourdieu, Pierre. Classificação, desclassificação, reclassificação. In: Nogueira, Maria Alice; Catani, Afrânio. Escritos em educação. 2. ed. Petrópolis: Vozes, 1999. p. 145-183. Сharlot, Bernard. Pour le savoir, contre la stratégie. In: Dubet, François (Org.).École, famille: le malentendu. Paris: Éditions Textuel, 1997.p. 59-78.

Dubet, François. École, familles: le malentendu (Sommaire). Paris: Éditions Textuel, 1997. p. 11-42.

Érnica, Maurício; Batista, Antônio Augusto Gomes. Educação em território de alta vulnerabilidade social na metrópole: um caso na periferia de São Paulo. São Paulo: CENPEC, 2011. Informe de Pesquisa n. 3. 
. A escola, a metrópole, a vizinhança vulnerável. Cadernos de Pesquisa, São Paulo: Fundação Carlos Chagas; Campinas: Autores Associados, v. 42, n. 146, maio/ago. 2012. [no prelo].

LAHire, Bernard. Sucesso escolar nos meios populares: as razões do improvável. São Paulo: Editora Ática, 2002.

2004.

. Retratos sociológicos. Disposições e variações individuais. Porto Alegre: Artmed,

Lomônaco, Beatriz Penteado; Garrafa, Thais Christofe. A complexidade da relação escola-família em territórios vulneráveis. Cadernos CENPEC, São Paulo: CENPEC, n. 6, p. 27-38, 2009.

Maloutas, Thomas. Efeitos de vizinhança e desempenhos escolares. In: Van Zanten, Agnès (Org.). Dicionário de educação. Petrópolis: Vozes, 2011. p. 288-291.

Montandon, Cléopâtre. As práticas educativas parentais e a experiência das crianças. Educação E̋ Sociedade, Campinas: CEDES, v. 26, n. 91, p. 485-507, maio/ago. 2005.

Ribeiro, Luiz César Queiróz; Kaztman, Rubén. A cidade contra a escola: segregação urbana e desigualdades educacionais em grandes cidades da América Latina. Rio de Janeiro: Letra Capital, FAPERJ; Montevidéu, Uruguai: IPPES, 2008.

Sant'Anna, Maria Josefina Gabriel. O papel do território na configuração das oportunidades educativas: efeito escola e efeito vizinhança. In: CARnEIro, Sandra de Sá; Sant'Anna, Maria Josefina Gabriel (Orgs.). Cidade: olhares e trajetórias. Rio de Janeiro: Garamond, 2009. p. 167-192.

\section{SOBRE OS AUTORES}

Hamilton Harley de Carvalho-Silva é mestre em educação pela Universidade de São Paulo (USP). Pesquisador do Centro de Estudos e Pesquisas em Educação, Cultura e Ação Comunitária (CENPEC).

E-mail: hamiltonharley@usp.br

Antônio Augusto Gomes Batista é doutor em educação pela Universidade Federal de Minas Gerais (UFMG). Pesquisador do Centro de Estudos e Pesquisas em Educação, Cultura e Ação Comunitária (CENPEC). E-mail: antonio.batista@cenpec.org.br

Luciana Alves é mestre em educação pela Universidade de São Paulo (USP). Pesquisadora do Centro de Estudos e Pesquisas em Educação, Cultura e Ação Comunitária (CENPEC).

E-mail: luciana.alves@cenpec.org.br 
HAMILTON HARLEY DE CARVALHO-SILVA, ANTÔNIO AUGUSTO GOMES BATISTA E LUCIANA ALVES

\section{A escola e famílias de territórios metropolitanos de alta vulnerabilidade social: práticas educativas de mães "protagonistas"}

$\mathrm{O}$ artigo apresenta resultados de uma investigação que teve por objetivo explorar relações com a escola de famílias moradoras de territórios de alta vulnerabilidade social. Examina práticas educativas de um grupo de mães, aqui consideradas "protagonistas", caracterizado por realizar fortes investimentos na escolarização dos filhos, mesmo que expostas a grandes riscos sociais. A coleta de dados foi realizada por meio de entrevistas semiestruturadas e da observação das famílias, moradoras na periferia da Zona Leste de São Paulo. A análise foi realizada por retratos sociológicos. As conclusões mostram que as mães empreendem alguns esforços, entre outros, 
para a escolha do estabelecimento de ensino, o acompanhamento da rotina escolar e do dever de casa e o controle das interações sociais dos filhos com o território.

Palavras-chave: relações família-escola; vulnerabilidade social; práticas educativas.

\section{Schools and families in metropolitan territories with high social vulnerability: educational practices of "protagonist" mothers}

This article presents the results of an investigation whose goal was to explore the relationships that families residing in territories with high social vulnerability have with schools. It examines the educational practices of a group of mothers, herein considered as "protagonist" mothers, who, despite being exposed to major social risks, characteristically make significant investments in their children's education. Data was collected through semi-structured interviews and by observing these families, who reside in periphery areas on the east side of São Paulo city. Analysis was done using sociological profiles. Conclusions show that these mothers make an effort, among others, to choose schools, to monitor their children's academic routines and homework and to control their children's social interactions with the territory.

Keywords: family-school relations; social vulnerability; educational practices.

\section{La escuela y familias de territorios metropolitanos de alta vulnerabilidad social: prácticas educativas de madres "protagonistas"}

El articulo presenta resultados de una investigación que tuvo por objetivo explorar relaciones con la escuela de familias habitantes de territorios de alta vulnerabilidad social. Examina prácticas educativas de um grupo de madres, aqui consideradas protagonistas, caracterizado por invertir fuertemente en la escolarización de los hijos, aunque expuestas a grandes riesgos sociales. La recolección de datos se realizó por medio de entrevistas parcialmente estructuradas y de la observación de las familias, en los alrededores de la Zona Este de São Paulo. El análisis se realizó por medio de retratos sociológicos. Las conclusiones muestran que las madres emprendenesfuerzos, como la elección del establecimiento de enseñanza, el acompañamiento de la rutina escolar y de la tarea de casa y el control de las interacciones sociales de los hijos con el territorio, entre otros.

Palabras clave: relaciones familia-escuela; vulnerabilidad social, prácticas educativas. 